\title{
Innovative GIS technology for forest monitoring: ForestLink
}

\author{
${ }^{1}$ S.R. Tchoffo, ${ }^{1}$ N. Rodrigue, L. ${ }^{1}$ Moutoni, ${ }^{1}$ G.T. HANDJA \\ ${ }^{1}$ Forêts et Développement Rural (FODER), Yaounde, Cameroon \\ Rainforest Foundation UK (RFUK), London, United Kingdom \\ srtchoffo@yahoo.fr,rtngonzo2002@yahoo.fr,moutoluc@yahoo.fr, georgesthierryh@ rainforestuk.org
}

\begin{abstract}
:
Covering about 180 million hectares, the Congo Basin is the second largest contiguous rainforest on the planet after the Amazon. But logging companies operate there at a frantic pace, sometimes illegally and to the detriment of the local communities that are the custodians of these forests, and who often live in poverty and lack basic infrastructure. Instead, a good management of these forests can significantly contribute to improving the living conditions of these populations, for instance by generating timber royalties that can be used for providing services or building infrastructures that benefit local communities. Communities themselves can play an important role in monitoring the forest operators' activities. To support them in doing so, British NGO The Rainforest Foundation UK and the Cameroonian association Forêts et Développement Rural have successfully developed and piloted technology in Cameroon which enables communities to capture and transmit geo-referenced reports of forest illegalities to a central database in near real-time, even from areas where there is no mobile phone or internet connectivity. The system has many potential applications and is easily adaptable to different kinds of forest monitoring, including for instance wildlife populations, poaching, positive achievements under initiatives such as REDD, etc.
\end{abstract}

Keywords: Cameroon, Forest monitoring, geo-referenced report, GIS, natural resources, real-time.

\section{INTRODUCTION}

Sustainable development is development that takes into account economic, social and environmental aspects. Today, companies are increasingly called upon to assume their social and environmental responsibility to ensure the sustainable management of natural resources. In parallel, and in the interests of local and indigenous populations that depend on natural resources, civil society organisations work in synergy for the preservation of forest resources whose irrational use implies a 
significant loss for States, rural populations and the international community as a whole. Indeed, natural resources are vital to rural life and livelihoods: they provide material resources, goods and services necessary for monitoring and security, but also for well-being and freedom.

The World Bank ("A Revised Forest Strategy for the World Bank Group”, October 2002 ) estimates that financial losses due to illegal logging and illegal timber trade at 10 to 15 billion dollars per year, about $10 \%$ of the world total value. For instance, the State of Cameroon is losing about 100 million dollars/year due to illegal logging (Reuters, quoted in the report: "[Note des ONG sur la lutte contre l'exploitation illégale du bois et le commerce lié ] Note of NGOs on the fight against illegal logging and related trade" published by the NGOs WWF, Greenpeace, les Amis de la Terre and France Nature Environnement).

Moreover, the illegal exploitation of natural resources in developing countries often contributes to fuelling conflict. For instance, Global Witness has recently denounced that in the Central African Republic, some forest companies contributed to finance the conflict in which the country has been plunged since 2013 ("Blood Timber", July 2015). Participatory mapping and independent monitoring of forest activities undertaken with local and indigenous communities in the Congo Basin by the Rainforest Foundation UK (RFUK) and the Cameroonian association Forêts et Développement Rural (FODER) have helped to highlight communities' dependence of the forest through the documentation of their livelihood activities (hunting, gathering, farming ...) and also to overcome the difficulty of rapid transmission of information on illegal logging to the competent authorities.

More concretely, in 2014, RFUK and FODER developed a community-based real-time forest monitoring system that could help improve how forests are protected and governed. The objective of this system, called "Forestlink", is to improve forest governance by providing enforcement and other agencies relevant information on illegal logging in real-time, including from areas that do not have 
internet and telephone connection. The system uses geomatics technologies combined with a smartphone or digital tablet connected to a satellite communication network. It was tested with two communities in Cameroon, in order to ascertain that the data collection and transmission tools were suitable for use by communities, and that the data collected and transmitted was correctly received, stored and made readily available in a central database, so that it could reach competent authorities and other relevant actors.

\section{TOOLS AND METHODOLOGY}

ForestLink was developed in response to the concerns of NGOs and communities on the monitoring of natural resources. It was thus designed to be used independently by communities. The system consists of several components which are: the hardware (tablet, transmitter), the software (odk collect and transmitter), the data (GIS, multimedia and descriptive data), the procedure (methodological guide and technical guide) and the users.

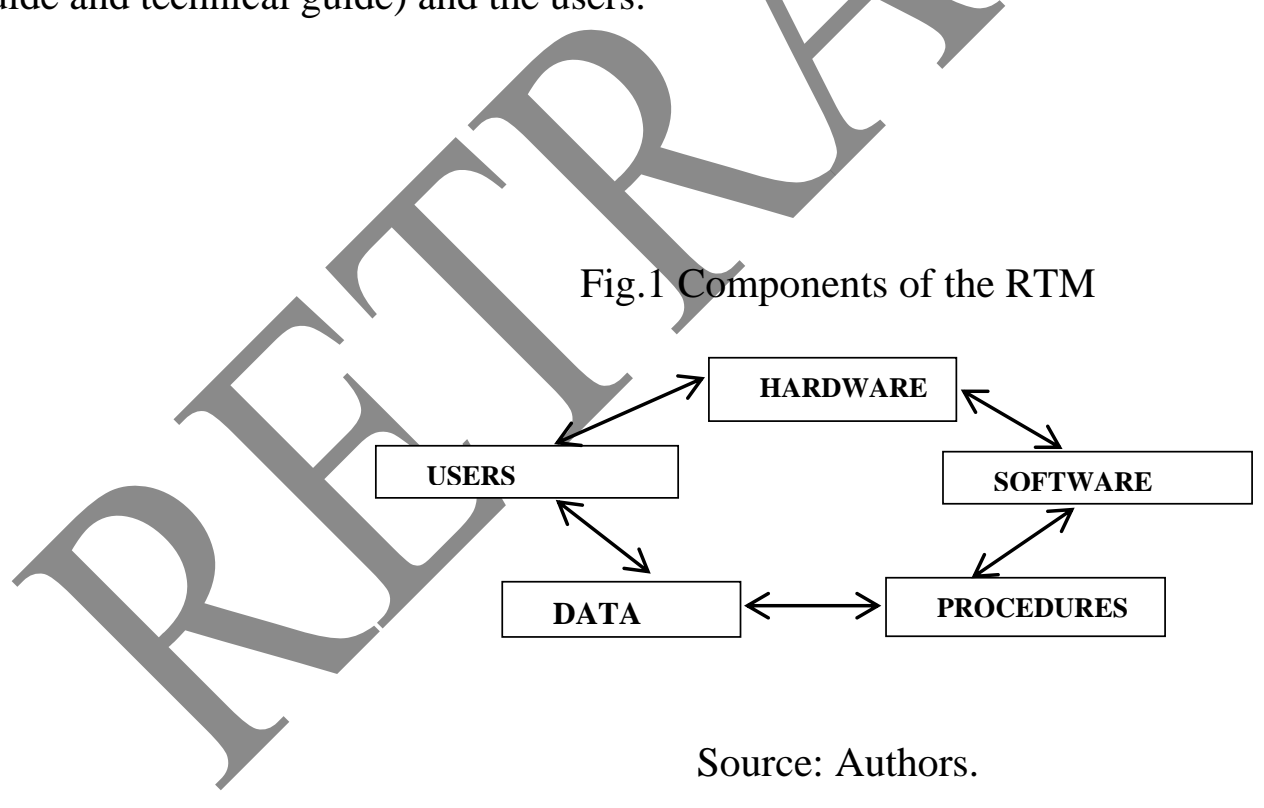

In addition to these main components, some accessory tools were also used during the test to support data collection in the field, and particularly for taking measurements on the illegalities observed: a clinometer for measuring slopes, and a tape measure for measuring distances. It is the illegalities to be 
observed and the measurements to be taken that will determine what -if any-additional tools are required. According to the FAO, many countries prohibit the dragging of wood on slopes greater than 30 percent $\left(17^{\circ}\right)$ during forwarding (Source: FAO Model Code of Forest Harvesting Practice). According to Forest Intervention Standards in Cameroon (1998, Article 15, P. 16), the "holder of a logging title must keep intact a wooded strip with a width of $30 \mathrm{~m}$, measured from the natural high water line on the edge of a sailing area".

In the tablet or smartphone, a "grid of illegalities" presenting the different categories and types of illegalities to be observed by communities was integrated.

Fig. 2: Conceptual Model of the illegality grid in forestry.

\begin{tabular}{|c|c|c|c|c|c|c|c|c|c|c|c|c|c|c|c|}
\hline Catégorie & $\begin{array}{l}\text { Aspect de } \\
\text { osserver }\end{array}$ & illégalités signalée & $\begin{array}{l}\text { Specification de } \\
\text { rillegolite }\end{array}$ & indicateurs 1 & Indicateurs 2 & 1 & 2 & 3 & 4 & 5 & 6 & 7 & 8 & 9 & 10 \\
\hline \multirow[t]{5}{*}{$\begin{array}{l}\text { Opdrations } \\
\text { forestiéres }\end{array}$} & \multirow[t]{5}{*}{ Limites } & $\begin{array}{l}\text { Inexistence d'un layon } \\
\text { indiquant is limite }\end{array}$ & & & & & & & & & & & & & \\
\hline & & $\begin{array}{l}\text { II n'y a ni plaques de } \\
\text { signalisation a la } \\
\text { peinture rouge ni } \\
\text { essences b croissance } \\
\text { rapide sur les limites }\end{array}$ & & & & & & & & & & & & & \\
\hline & & \multirow{3}{*}{$\begin{array}{l}\text { Exploitation de bois au- } \\
\text { dela des limites de } \\
\text { l'Assietre Annuelle de } \\
\text { coupe (AAC) ou de la } \\
\text { parcelle }\end{array}$} & Tiges abattues & $\begin{array}{l}\text { N'de tipes sbottues } \\
\text { observies hors } \\
\text { limites: }\end{array}$ & & & & & & & & & & & \\
\hline & & & Grumes & $\begin{array}{l}\text { Node grumes } \\
\text { obsentes hors } \\
\text { llimites: }\end{array}$ & & & & & & & & & & & \\
\hline & & & Billes & 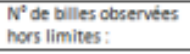 & & & & & & & & & & & \\
\hline
\end{tabular}

Source: RFUK, FODER

The grid was developed in relation to the laws and regulations in force in Cameroon, while also taking into account what communities can readily observe on the ground. A forest operation can only be presumed illegal if there are legal provisions proscribing it. In other words, we can only speak of an activity being illegal if there is a legal ban on it. It is also important to stress the fact that, while the system can provide accurate and timely information on presumed illegalities, only the competent authorities have the authority to punish violations.

Once the system established, RFUK and FODER tested its functionality, effectiveness and suitability for community use. As a preliminary step, we first tested the performance of the tablet GPS 
and of the satellite modem under different types of canopy cover (open, moderately dense, dense and very dense). Afterwards, community representatives were trained on the use of the system (equipment, methodology for collection and transmission of data). The system was then tested with communities in the field, following a two-step process: community observers were initially accompanied and closely supported by FODER, but in a second phase they proceeded to do the monitoring independently. In both these stages, community observers documented suspected cases of illegalities in the forest area around their community, and transmitted this information to the central database via satellite connection. The veracity of some of this data was then verified in the field by FODER using a predesigned verification form. The verification stage allowed for collecting additional information about the incidents reported -for instance on the approximate date when it took place, whether it was an isolated or a regular occurrence, its author, possible causes and observed impacts, etc.- and for documenting it visually.

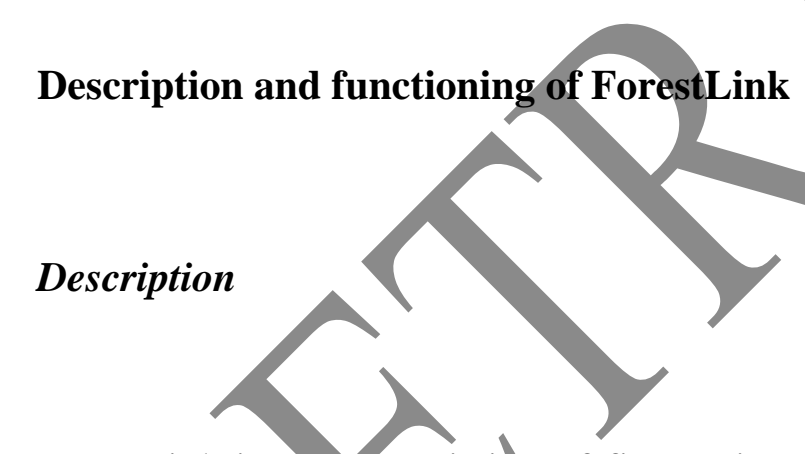

ForestLink is a set consisting of five main components: hardware, software, procedures, data and users

Regarding the hardware, ForestLink includes the following tools:

- A smartphone or digital tablet equipped with an Android operating system (the test was performed on version 4.2) that supports applications;

- A transmitter/ Raspberry Pi, which is like a computer equipped with a wireless key and receives the information collected on the smartphone or tablet; 
- A satellite modem / Rockblock, which receives data from the transmitter and sends it to the server using the satellite signal;

- A Smart Battery that supplies power to the transmitter during the transmission phase.

Thus, the smartphone or digital tablet serves to collect and verify data, while the Raspberry Pi and Rockblock allow for the transmission of data.

Fig. 3,4,5: Smartphone, transmission hardware, Smart battery.
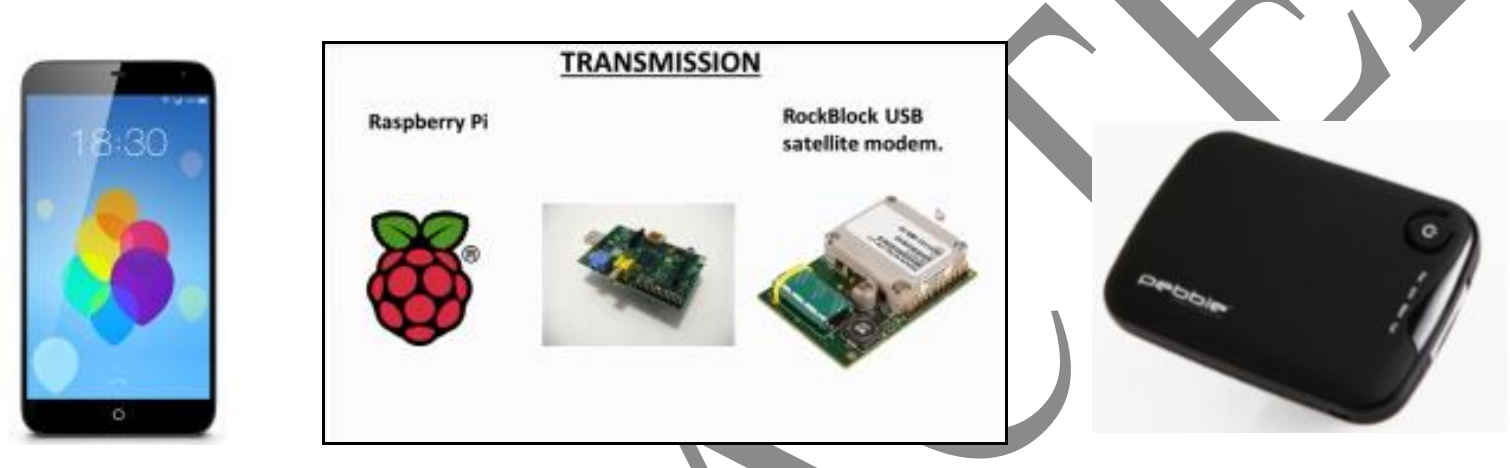

\section{Source: RF UK, FODER.}

Regarding the software component, we used two applications compatible with the Android operating system.

The $O D K$ collect application, which is used for collecting and verifying the data;

- The transmitter application, which sends the data collected to the transmitter (hardware) through the wifi connection.

With regard to the procedures, RFUK and FODER developed two guides on the use of the system: 
- Technology Guide: it provides technical guidance on the components, functioning and use of the system;

- Methodology Guide: it outlines the methodology to use in the office, in the community and on the field to carry out a good observation activity.

With regard to the data, the system takes into account different types of data (geo-referenced and text). This data allows to properly documenting a case of illegality.

The last component consists of the communities and the NGOs who were the users of system during the test.

\section{Functioning}

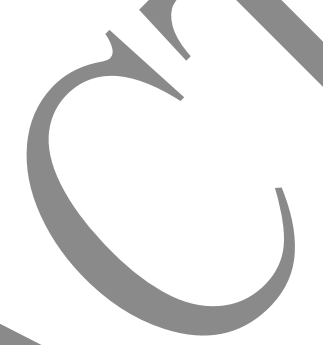

ForestLink is a system that operates sequentially (collection-transmission-checking) at each of its various stages.

Collection is made with a smartphone or digital tablet equipped with the ODK collect application. Once the observer discovers a suspected case of illegality, he activates his smartphone or tablet and launches the $O D K$ collect application. The application has an illegality grid with the different types of illegality that can be observed and documented on the ground. The user first needs to select the area of activity in which the illegal activity being observed would fall (e.g.: forest activities, protection of the environment, respect of social and environmental obligations). After this, he/she is to select the specific aspect being observed (e.g.: under forest activities, it could be an illegality related to limits, marking, etc.). Then, the specific type of illegality needs to be identified (e.g.: cutting off limits, cutting of protected species, etc.) and indicators and measurements can provided where relevant (e.g.: distance between the log and the limit, number of protected specifies cut, etc.). The information is therefore provided gradually, and at the end of the questionnaire the report is associated with the 
geographical coordinates $(\mathrm{x}, \mathrm{y})$ of the location where the observation was made. The georeferenced report can then be saved on the tablet/smartphone, and the user can start recording a new observation.

Once data has been collected and recorded on the tablet with the corresponding GPS coordinates, it can then be sent to the transmitter. In order to do so, the tablet/smartphone and also the transmitter first need to be switched on. When the transmitter is on, it will provide Wi-Fi access for the tablet to connect wirelessly and allow the tablet to transfer the collected information to the transmitter.

Once the transmitter receives data from the tablet, it will start processing it so it can be sent via satellite. It will then try to capture and establish a satellite connexion. When registered, and receiving a good signal, the data will be sent from the transmitter to the satellite. From the satellite, the data is passed on to the online GIS platform of ForestLink ( ('http: //monitor.mappingforrights.org'), where it is stored. All the stages of the collection and transmission process can be completed by community observers trained to use the system.

During the test, the verification was made by FODER, which relied on the information sent by community observers. Some of the illegality reports sent from the field were selected for verification. Each report or observation has a unique code that identifies it. Once in the field, FODER verified the accuracy of each observation and filled in a predesigned verification form on the tablet. Verification meant not only ensuring that the obseryation corresponded to one of the illegalities listed in the grid, but also that it had been adequately documented and that the measurements and indicators given in the original report were correct. At the same time, the verifier collected additional information about the presumed illegality and documented it visually by taking a picture. The verified data was then incorporated to the online GIS platform.

Fig. 6: Preview of the online platform. 


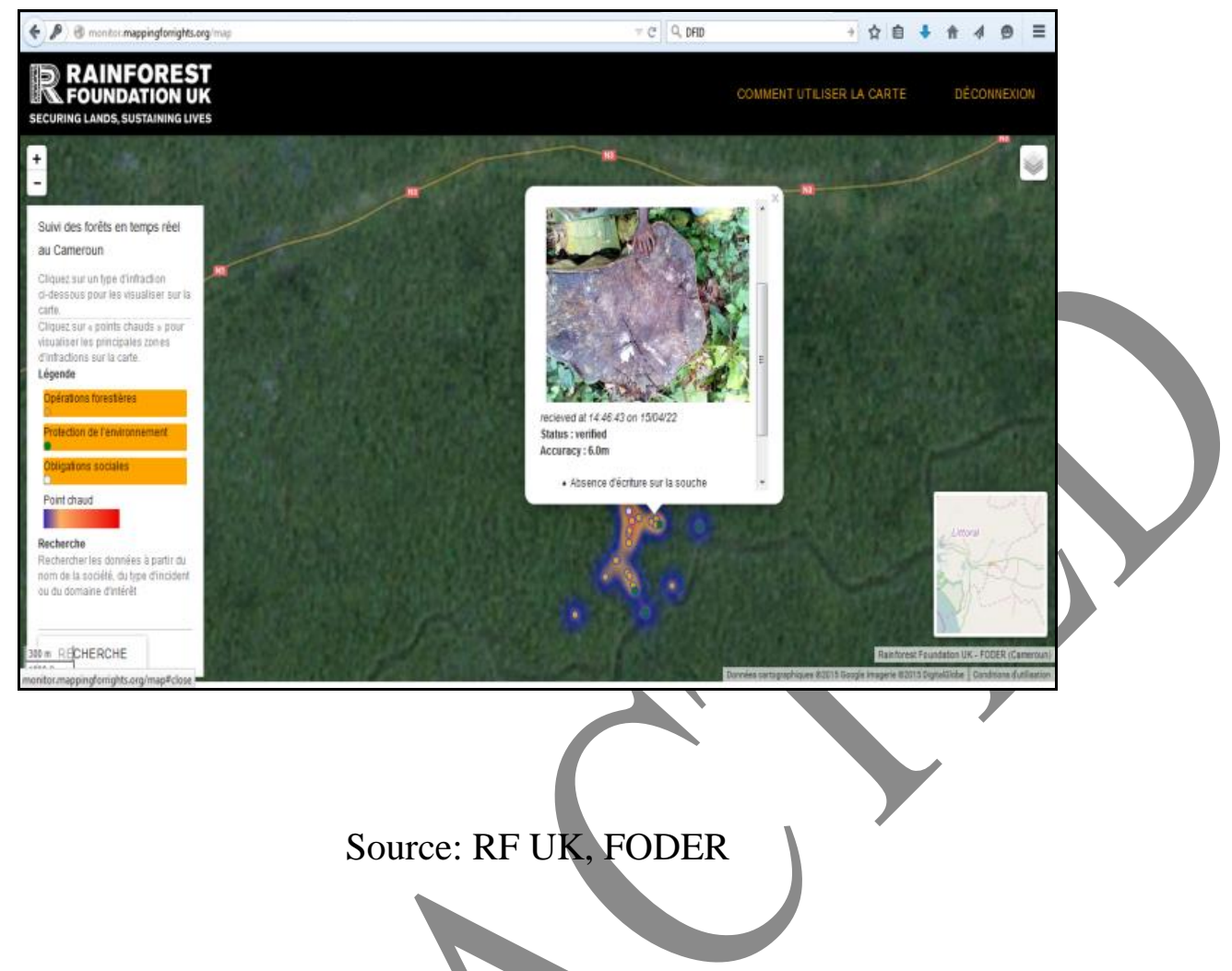

Therefore, the system allows for storing and for making information on presumed forest illegalities available to enforcement agencies and all those with an interest in putting a stop to illegal logging. The platform allows for viewing all the presumed illegalities reported and at the same time for knowing which of them have been subject to verification.

\section{RESULTS}

Following the development of this technology, tests were conducted on the following aspects: the collection, sending use of the tool by communities and verification of data.

In terms of collection, our specialists and community observers collected and sent one hundred (100) observations on alleged illegal logging activities. Among the data sent, forty (40) were collected and sent by community observers independently.

In terms of verification, twenty (20) out of forty (40) observations collected and sent by community observers were checked by our specialists. It was ensured that all the observations received matched 
the observations transmitted. In short, the system works well and can be used autonomously by communities.

\section{Discussion}

On 24 June 2015, RFUK organized presented the system and its challenges and opportunities for improving forest governance at the Royal Institution in London. I t was found that ForestLink allows for significantly speeding up the process of transmission of alerts related to illegal forest activities from local communities to the competent law enforcement authorities. Communities generally do not have enough means to make regular trips and make the information available to relevant actors. This tool can potentially contribute to dramatically improve forest governance and thus promote transparency in the forest sector. ForestLink is applicable to many other fields where spatial information in real time can support immediate actions or decisions. We can mention mining, management and monitoring of the environment, sustainable land management, water resource management and even the violation of human rights. The grid of illegalities can be developed and customized to each sector of activity.

As for the limitations of the system, for now, the surmountable technical constraint is the power source for the components that need charging. RFUK and FODER have envisaged the solution of using a source of sustainable energy, and particularly transportable solar panels. Both partners are still working on this aspect to find the most appropriate solution for rural communities, no matter their location.

\section{Conclusion and recommendation}

In view of the above, we can say that ForesLink is used to collect and send near real-time spatial information about illegal forest activities. The information sent is receivable in their entirety with spatial references. The system can be used by local communities independently, provided that they are trained in its use. We believe that this system can effectively contribute to improving forest governance. The 
system could also encourage the various stakeholders to be more vigilant and respectful of sustainable management of natural resources. Progress still needs to be made on sustainable energy supply sources by communities. Further research on the issue could well focus on how communities can be given incentives for a consistent use the system. Another big challenge is the integration of the system by government agencies to strengthen forest monitoring. It is recommended that users of the system become familiarised with and follow the procedures pertaining to it before its use.

\section{Acknowledgements}

Our thanks go first to the two organisations that contributed to the drafting of this article, RFUK and FODER. We also thank the communities of Mapubi and Ndokok in Camreoon who participated in the test of this innovative approach. Finally, we thank all of those that cannot be specifically named and who participated directly or indirectly to the development of this tool.

This initiative is supported by UKAID, the British Department for International Development (DfID).

\section{REFERENCES}

Alison H., 2015. Commerce de Bois Illégal L'Action au Cameroun, Chatham House. London.

Beaudry, É., 2011. Rédiger et publier un article scientifique. Université de Sherbrooke, Canada.

Bédard Y., 1997. Spatial OLAP, Paper presented at the Annual Forum on R\&D, Geomatics VI,

Canadian Institute of Geomatics, Montreal, Canada.

Bédard, Y., 2005. Integrating GIS and OLAP: a New Way to Unlock Geospatial Data for Decisionmaking, Directions on Location Technology and Business Intelligence, Canada.

Brack D. et Léger C., 2013, Etudier les problèmes de crédibilité des Accords de Partenariat 
Volontaire. Examen des initiatives d'observation indépendante et enseignements à en tirer. Londres, Global Witness.

Brack, D., Léger, C, Spt. 2013. Examen des initiatives d'observation indépendante et enseignements à en tirer, Global Witness, London.

Carret J.-C., 2000. La réforme de la fiscalité forestière au Cameroun : Débat politique et analyse économique. Bois et forêts des tropiques, Centre d'économie industrielle de l'Ecole des mines de Paris, France.

Cerutti P. O. et Lescuye G., 2011, Le marché domestique du sciage artisanal au Cameroun, État des lieux, opportunités et défis, CIFOR, Bengor.

Global Witness, July 2015, Blood Timber. How Europe helped fund war in the Central African Republic., London.

Grégoire L., Emmanuelle N., Grégory J., 2009. Noté des ONG sur la lutte contre l'exploitation illégale du bois et le commerce lié, pp 1, WWF, Greenpeace, les amis de la terre et France Nature Environnement, France.

Hédin L., 1930. Étude sur la forêt et les bois du Cameroun sous mandat français, Librairie Larose, Paris, France.

Institut Atlantique d'Aménagement du Territoire (IAAT Poitou Charente), 2009. Système d'information Géographique et Territoires, CEDEX, France.

Laprise R., 2009. Quelques conseils pour la rédaction d'un article pour publication dans une revue avec comité de lecture, pp 1-2.

Miller H., Han H., 2001. Geographic Data Mining and Knowledge Discovery. CRC Press, Florida.

Ministry of Environment and Forestry of Cameroon, 1998, Normes d'Intervention en milieu Forestier, pp 16, Yaoundé. 
Patersenet, K. Wohlin C., 2009. Context in industrial software engineering research, $3^{\text {rd }}$ International Symposium on empirical Software and Measurement, ESEM, Canada

Runeson P. and Host M., 2009. Guidelines for conducting and reporting case study research in software engineering, Springer US, USA.

World Bank Group, 2002. A Revised Forest Strategy for the World Bank Group, pp 7. WB, Washington, DC.

\section{Webography}

http://forest4dev.org/

http://monitor.mappingforrights.org

http://www.fao.org/docrep/v6530f/v6530f08.htm

http://www.rainforestfoundationuk.org/

http://www.wri.org/

http://www.fao.org/docrep/v6530f/v6530f08.htm 